\title{
Atuação de profissionais da educação na inclusão escolar do aluno com deficiência intelectual
}

Anaí Cristina da Luz Stelmachuk* Marcos José da Silveira Mazzotta**

\section{Resumo}

A pesquisa investigou como professores regentes e supervisores escolares têm atuado em relação aos alunos com deficiência intelectual, tendo em sala de aula um auxiliar. A fundamentação teórica baseou-se em literatura especializada e pesquisa documental referente à legislação brasileira e publicações oficiais sobre Educação Especial. A pesquisa de campo seguiu a abordagem qualitativa, tendo como sujeitos 10 supervisores escolares e 16 professoras regentes de classes dos anos iniciais do Ensino Fundamental da Rede Pública Municipal de União da Vitória - PR. Para a coleta de dados, os sujeitos responderam a questionários e $30 \%$ dos supervisores e $31,25 \%$ das professoras foram entrevistadas. As respostas foram categorizadas em: significado de inclusão escolar, conceito de deficiência intelectual e objetivo educacional em relação ao aluno com deficiência intelectual, facilidades e dificuldades da inclusão desse aluno nas escolas e condições de apoio à inclusão. Após análise dos dados constatou-se que: os auxiliares são solicitados à Secretaria Municipal da Educação pelas escolas; $88,46 \%$ dos sujeitos da pesquisa orientam os auxiliares. $69,23 \%$ sentem-se parcialmente preparados e $23,07 \%$ sentem-se preparados para tal função. Professoras consideram que seus alunos com deficiência intelectual apresentam maior necessidade de apoio na área acadêmica. Supervisores e professoras consideram que o apoio do auxiliar em sala de aula reflete positivamente no desenvolvimento acadêmico e social dos alunos, evidenciando ressalvas em relação ao desenvolvimento da autonomia. Os sujeitos questionam o perfil e a formação dos auxiliares e sugerem formação continuada para estes e para si.

Palavras-chave: Profissionais da Educação; Inclusão Escolar; Deficiência Intelectual.

\section{Performance of the education professionals concerning the school inclusion of the student with intelectual disability}

\begin{abstract}
This research investigated how regular teachers and school-unit supervisors have behaved in relation to students with intellectual deficiencies, having in view the addition of an assistant teacher in the classroom. The theoretical fundaments were based both on specialized literature as well as documented research regarding

\footnotetext{
* Mestre pela Universidade Presbiteriana mackenzie, São Paulo, Brasil. Professora Secretaria Municipal da Educação de União da Vitória, Uniao da Vitoria, PR, Brasil.

** Professor Titular do Programa de Pós-graduação em Distúrbios do Desenvolvimento da Universidade Presbiteriana mackenzie, São Paulo, Brasil.
} 
the Brazilian legislation and official publications on Special Education. The field research followed the qualitative approach, and had as subjects 10 school supervisors and 16 regular teachers from the first years in Elementary School at the Public Municipal Network from the town União da Vitória - Paraná State. For the data collection the subjects answered questionnaires and $30 \%$ of the supervisors and $31.25 \%$ of the teachers were interviewed. The answers were categorized as: meaning of school inclusion; concept of intellectual deficiency, and educational aims in relation to the intellectually deficient student; facilities and difficulties involving the inclusion of such students in the regular schools; and conditions for the support to the inclusion. After the data was analyzed it was verified that: the assistants are requested the Municipal Board of Education by the schools; $88.46 \%$ of the subjects in this research give directions to the assistants. $69.23 \%$ feel partially prepared and $23.07 \%$ feel prepared for such a position. Teachers consider that students with intellectual deficiency present a greater necessity of support in the academic area. Both, supervisors and teachers consider that the support of an assistant teacher in the classroom reflects positively in the academic and social development of the students, evidencing safeguards in relation to the development of the autonomy. The subjects questioned the profile and educational background of the assistants and suggested continuing education for such professionals as well as for themselves.

Keywords: Education Professionals; School Inclusion; Intellectual Disability.

\section{Introdução}

No Brasil, a atual Lei de Diretrizes e Bases da Educação Nacional, Lei 9.394 de 20 de dezembro de 1996, dispõem em seu Artigo $4^{\circ}$ que "O dever do Estado com educação escolar pública será efetivado mediante a garantia de atendimento educacional especializado gratuito aos educandos com necessidades especiais, preferencialmente na rede regular de ensino" (BRASIL, 1996). Entretanto, segundo Mazzotta (2003), a Lei de Diretrizes e Bases da Educação Nacional 4.024 de 1961, em seu Artigo 88, já assegurava que a educação das pessoas excepcionais, dentro do possível, deveria acontecer no sistema geral de ensino, com o propósito de integrá-las na comunidade. Porém, as políticas públicas nacionais não garantiam o cumprimento desta lei. Com o crescimento do movimento da sociedade em favor da inclusão social e escolar, ações visando o acesso e a permanência da pessoa com necessidades educacionais especiais na escola comum têm sido desenvolvidas.

No artigo 2. da Resolução CNE/CEB n $2 / 2001$, as Diretrizes Nacionais para a Educação Especial na Educação Básica determinam que "os sistemas de ensino devem matricular todos os alunos, cabendo às escolas organizarem-se para o atendimento aos educandos com necessidades educacionais especiais, assegurando as condições necessárias para uma educação de qualidade para todos" (BRASIL, 2001). Tal atendimento, conforme documento elaborado pela Secretaria de Educação Especial do Ministério da Educação intitulado 
Política Nacional de Educação Especial na Perspectiva da Educação Inclusiva (BRASIL, 2008), é denominado atendimento educacional especializado, no qual a educação especial direciona suas ações para o atendimento de suas especificidades no processo educacional e orienta a organização de redes de apoio, formação continuada, identificação de recursos, serviços e o desenvolvimento de práticas colaborativas.

O atendimento educacional especializado contempla ações voltadas a alunos com deficiência, transtornos globais do desenvolvimento e superdotação. $\mathrm{Na}$ organização destes atendimentos, os sistemas de ensino devem "disponibilizar as funções de instrutor, tradutor/intérprete de Libras e guia-intérprete, bem como de monitor ou cuidador dos alunos com necessidade de apoio nas atividades de higiene, alimentação, locomoção, entre outras, que exijam auxílio constante no cotidiano escolar." (BRASIL, 2008).

Dentre os levantamentos sobre alunos com deficiências matriculados em classes comuns nas escolas regulares, realizados pelo INEP - Instituto Nacional de Estudos e Pesquisas Educacionais Anísio Teixeira, em 2006, o maior número de matriculas referia-se a alunos com deficiência intelectual (BRASIL, 2006).

É oportuno destacar quea Associação Americana de Retardo Mental - AAMR, em definição datada de 2002, considera o retardo mental como: "uma incapacidade caracterizada por importantes limitações, tanto no funcionamento intelectual quanto no comportamento adaptativo, está expresso nas habilidades adaptativas conceituais, sociais e práticas. Esta incapacidade tem início antes dos 18 anos" (AAMR, 2006, p. 33-34). Esta definição está vinculada a cinco hipóteses:

a) As limitações no funcionamento atual devem ser consideradas dentro do contexto dos ambientes da comunidade típicos das pessoas da mesma faixa etária e da mesma cultura do indivíduo.

b) A avaliação válida considera a diversidade cultural e linguística, e também as diferenças nos fatores de comunicação, nos fatores sensoriais, motores e comportamentais.

c) Em cada indivíduo, as limitações frequentemente coexistem com as potencialidades.

d) Um propósito importante ao descrever as limitações é desenvolver um perfil dos apoios necessários.

e) Com os apoios personalizados durante um determinado período de tempo, o funciocnamento cotidiano da pessoa com retardo mental em geral melhora. (AAMR, 2006, p. 34)

Cabe salientar que, a partir de 2007, a AAMR passou a ser denominada Associação Americana de Deficiência Intelectual e de Desenvolvimento - 
AAIDD. Em seu novo manual, datado de 2010, o termo retardo mental foi substituído por deficiência intelectual, porém sua definição continuou a mesma.

Segundo a AAMR, para melhorar seus resultados pessoais de independência, relacionamentos, participação na escola e na comunidade, e bemestar pessoal, as pessoas com deficiência intelectual devem receber apoios especiais e considera que "apoios são recursos e estratégias que visam a promover o desenvolvimento, a educação, os interesses e o bem estar de uma pessoa, e que melhoram o funcionamento individual." (AAMR, 2006, p.141).

Para prover os apoios adequados é necessário saber quais são as necessidades educacionais especiais dos alunos com deficiência intelectual, pois estas variam de sujeito para sujeito nas cinco dimensões que constituem o conceito de deficiência intelectual: habilidades intelectuais, comportamento adaptativo, participação, interações e papéis sociais, condições de saúde e contexto (ambiente e cultura).

Este conhecimento deve ser de todos os profissionais envolvidos no processo educacional do aluno com deficiência intelectual e pode ser obtido através da observação direta, do contato com a família, da troca de informações entre profissionais de diversas áreas que atuam com a criança, de informações contidas em avaliações no contexto, avaliações pedagógicas, psicológicas, etc., às quais o aluno tenha sido submetido

Segundo Mazzotta (1998) "é na convivência com os outros e com o meio ambiente que as necessidades de qualquer ser humano se apresentam". Portanto, o autor considera relevante que a identificação das necessidades educacionais como especiais e as orientações sobre os atendimentos aos alunos que as tenham, aconteçam de forma criteriosa pelos profissionais envolvidos e pela família do aluno. Ressalta, ainda, que grande parte das necessidades educacionais de alunos com deficiência pode ser atendida com os recursos regulares da própria escola comum. Entretanto, quando houver a presença de necessidades educacionais, que estejam além do atendimento proporcionado pelos professores e recursos das escolas comuns, será necessário que se conte com serviços educacionais propiciados por professores especialmente preparados (MAZZOTTA, 1998).

No início dos anos oitenta, Mazzotta (1982, p.18) já afirmava que "não existe relação direta entre deficiência e educação especial". Quanto à Educação Especial e a relação entre o educando e a escola, o autor defende uma abordagem dinâmica que:

Baseada no princípio da não segregação, ou da inclusão, possibilita a melhor compreensão da relação concreta entre o educando e a educação escolar, já que comporta a organização de situações de ensino-aprendizagem mais condizentes com necessidades educacionais a atender, sejam elas comuns ou especiais. (MAZZOTTA, 2008, p.16) 
Nas Diretrizes Nacionais para a Educação Especial na Educação Básica de 2001, encontra-se que na organização das classes comuns será necessário prever flexibilizações e adaptações curriculares, metodologias de ensino e recursos didáticos diferenciados e processos de avaliação adequados ao desenvolvimento dos alunos que apresentam necessidades educacionais especiais, em consonância com o projeto pedagógico da escola, respeitada a frequência obrigatória (BRASIL, 2001).

Libâneo (2004) entende que um projeto pode ser considerado um esquema que representa uma ideia, uma meta, uma sequência de ações que irão orientar a prática e que no planejamento escolar, o que se planeja são atividades de ensino e aprendizagem, determinados por intencionalidade educativa que envolve objetivos, valores, atitudes, conteúdos, modos de agir dos educadores que atuam na escola. Para o autor (2004, p.151), o projeto pedagógico curricular expressa "a síntese das exigências sociais e legais dos sistema de ensino e os propósitos e expectativas da comunidade escolar".

Com base nestes conceitos, pode-se dizer que o planejamento das ações educacionais que ocorrem ao se formular o projeto político pedagógico de uma escola é oportunidade de torná-la inclusiva.

Encontra-se em documento intitulado Caderno de Apoio à Elaboração do Regimento Escolar, criado pela coordenação de gestão escolar da Secretaria do Estado da Educação do Paraná que uma das funções do coordenador pedagógico é "coordenar a elaboração coletiva e acompanhar a efetivação do Projeto Político Pedagógico e do Plano de Ação do estabelecimento de ensino." (PARANÁ, 2007, p.30).

O coordenador pedagógico mediará as ações entre os profissionais do ensino comum e do atendimento educacional especializado e sob sua responsabilidade está o acompanhamento dos estagiários das instituições de ensino nas atividades a serem desenvolvidas na escola (PARANÁ, 2007, p.30-33).

Entre as atribuições do professor estão a participação na elaboração, implementação e avaliação do Projeto Político-Pedagógico, a viabilização da igualdade de condições para a permanência do aluno na escola, a formação ética e o desenvolvimento da autonomia intelectual visando ao exercício consciente da cidadania. O professor deve, ainda, assegurar que no âmbito escolar não ocorra tratamento discriminatório em decorrência da diversidade entre os alunos (PARANÁ, 2007, p. 40-42).

Em se tratando de profissionais do atendimento especializado atuando na escola comum, no Parecer CNE $n^{\circ} 13$ e na Resolução CNE n 04 , ambos de 2009, do Conselho Nacional de Educação, encontra-se que o projeto pedagógico da escola de ensino regular deve institucionalizar a oferta deste atendimento prevendo em sua organização profissionais da educação, entre eles: tradutor e intérprete de Língua Brasileira de Sinais, guia-intérprete e outros que 
atuem no apoio, principalmente, às atividades de alimentação, higiene e locomoção (BRASIL, 2009).

Causa estranheza que entre os profissionais da Educação, constem os responsáveis pelo apoio às atividades de alimentação, higiene e locomoção, visto que para exercer tal função não são necessários conhecimentos pedagógicos.

Entretanto, cada profissional, independentemente do cargo que ocupa em uma unidade escolar, e a comunidade escolar como um todo, pode facilitar ou não, o processo de inclusão e desenvolvimento de cada aluno.

\section{Método}

Para a execução do trabalho realizou-se revisão bibliográfica e pesquisa de campo com enfoque qualitativo. Segundo Lüdke e André (1986, p.12), "ao considerar os diferentes pontos de vista dos participantes, os estudos qualitativos permitem iluminar o dinamismo interno das situações, geralmente inacessível ao observador externo".

A Resolução n 196/96 do Conselho Nacional de Saúde determina que toda pesquisa em andamento no país envolvendo seres humanos deve ser submetida à apreciação de Comitês de Ética em Pesquisa vinculados à Comissão Nacional de Ética em Pesquisa - CONEP (BRASIL, 2008). Para a realização da pesquisa de campo, o projeto da pesquisa foi submetido à avaliação do Comitê de Ética em Pesquisa da Universidade Presbiteriana Mackenzie, recebendo parecer favorável.

A pesquisa ocorreu na cidade de União da Vitória, situada no extremo sul do Estado do Paraná. Conforme dados referentes ao mês de abril de 2011, obtidos junto a Secretaria de Educação (SEMED) deste município, entre os 3.575 alunos matriculados nos anos iniciais do Ensino Fundamental de sua rede pública 1,3\%, ou seja, 46 , eram diagnosticados com deficiência intelectual e entre estes, dois apresentavam múltipla deficiência, estando a deficiência intelectual associada à deficiência física.

A pesquisa focou classes nas quais havia um ou mais alunos com deficiência intelectual associada ou não a outros diagnósticos e contavam com a presença de um auxiliar.

Os auxiliares são estudantes do ensino médio que cursam Magistério, ou estudantes de Pedagogia, ou de outro curso da área da Educação. São contratados como estagiários, tendo preferência os que possuem ou estão em formação na área da Educação Especial, porém poucos satisfazem este critério. Portanto, necessitam de orientação sobre sua atuação e os profissionais da escola, em contato direto com os auxiliares e com os alunos das classes com auxiliares, são os professores regentes e supervisores escolares. Tal situação 
justifica a escolha dos sujeitos da pesquisa: supervisores escolares e professores regentes de classes dos anos iniciais do Ensino Fundamental nas quais atue um auxiliar e estudem alunos diagnosticados com deficiência intelectual, em escolas da Rede Pública Municipal da cidade de União da Vitória.

Levantamento junto à SEMED sobre os profissionais da educação que se encaixavam neste perfil resultou em 10 supervisores escolares e 16 professoras regentes distribuídos em 10 escolas.

Importante esclarecer que, na rede municipal de União da Vitória, o termo "supervisor escolar" é atribuído ao profissional responsável pela coordenação pedagógica da escola.

Como instrumentos de pesquisa para a coleta de dados foram utilizados dois modelos de questionários. Um respondido individualmente pelos supervisores e o outro respondido individualmente pelas professoras. Os questionários foram compostos por perguntas fechadas, apresentando alternativas de respostas e perguntas abertas. Concordando com Sampieri, Collado e Lucio (2006), entende-se que as perguntas abertas são úteis quando não se tem a informação sobre as possíveis respostas das pessoas, ou estas informações são insuficientes, ou ainda quando se deseja aprofundar-se sobre uma opinião ou motivos de um comportamento.

Sampieri, Collado e Lucio (2006) afirmam que é comum ver estudos que utilizam diferentes métodos de coleta de dados e Lüdke e André (1986) indicam que o uso de entrevistas permite o aprofundamento sobre pontos levantados por outras técnicas. Neste estudo, além dos questionários, foram realizadas entrevistas de caráter complementar com 30\% dos supervisores e $31,25 \%$ dos professores sujeitos da pesquisa, totalizando três supervisores e cinco professoras entrevistados, distribuídos em três escolas. As entrevistas foram elaboradas de forma semi-estruturada contendo cinco perguntas. Conforme Sampieri, Collado e Lucio (2006), nas entrevistas semi-estruturadas o entrevistador baseia-se em um guia de assuntos ou questões, podendo introduzir mais questões para a precisão de conceitos ou obtenção de maiores informações sobre o tema desejado.

O consentimento para a realização da pesquisa de campo foi obtido através da assinatura de termo de consentimento livre e esclarecido pela Secretária Municipal de Educação, diretores responsáveis pelas instituições de ensino em que atuam os sujeitos da pesquisa e pelos próprios sujeitos da pesquisa.

Após o recebimento dos questionários preenchidos, partiu-se para a escolha randomizada dos entrevistados. Foram sorteadas três escolas, envolvendo três supervisoras e cinco professoras. As entrevistas aconteceram nas escolas em que os sujeitos atuam e a data e horário foram marcados por contato telefônico, de acordo com a disponibilidade dos entrevistados. 
As entrevistas foram transcritas e organizadas em quatro categorias: significado de inclusão escolar, conceito de deficiência intelectual e objetivo educacional em relação ao aluno com deficiência intelectual, facilidades e dificuldades da inclusão desse aluno nas escolas e condições de apoio à inclusão. Foram categorizadas também as respostas dos questionários.

Na sequência, para a melhor compreensão do fenômeno estudado, os dados obtidos foram analisados de acordo com referencial teórico que embasou o trabalho.

\section{Resultados}

Dados pessoais, profissionais e formação acadêmica dos supervisores:

Quadro 1 - Caracterização dos Supervisores

\begin{tabular}{|c|c|c|c|c|c|c|}
\hline Idade & Sexo & $\begin{array}{c}\text { Tempo como } \\
\text { supervisor }\end{array}$ & $\begin{array}{c}\text { Ensino } \\
\text { Médio }\end{array}$ & Graduação & Pós-Graduação & $\begin{array}{c}\text { Cursos } \\
\text { em EE }\end{array}$ \\
\hline 35 & M & 2 anos e 6 meses & M & P & MEA & DA \\
\hline 41 & F & 8 anos & M & P & Pp - ASE & \\
\hline 41 & F & 2 anos e 6 meses & M & $\begin{array}{c}\text { C-P } \\
\text { (cursando) }\end{array}$ & PESI & \\
\hline 42 & F & 18 anos & M & P & Pp - FE & \\
\hline 43 & F & 4 anos & M & A - C & ASE & \\
\hline 44 & F & 5 anos & M & P & Pp & \\
\hline 44 & F & 16 anos & M & Geo & PESI - ASE & \\
\hline 45 & F & 5 anos & M & P & PE & \\
\hline 45 & F & 2 anos e 6 meses & M - C & P - Ps & PE & DA \\
\hline 49 & F & 13 anos & M & Geo & PESI - ASE - & \\
\hline
\end{tabular}

Legenda: Sexo: F - Feminino, M - Masculino. Ensino Médio: $M$ - Magistério, C Contabilidade. Graduação: P - Pedagogia, Geo - Geografia, C - Ciências, A Administração, Ps - Psicologia. Pós-graduação: MEA - Metodologia do Ensino à Arte, Pp - Psicopedagogia, ASE - Administração e Supervisão Escolar, PESI - Pré-escola e Séries Iniciais, PE - Psicologia da Educação, GF - Geografia Física. Cursos em Educação Especial: DA - Deficiência auditiva.

Fonte: a autora 
Entre os supervisores escolares, a média de idade é de 43 anos e 11 meses. A média do tempo de atuação como supervisor escolar é de sete anos e seis meses. Todos são formados em magistério no Ensino Médio. Seis são graduados em Pedagogia, dois em Geografia, dois em Ciências. Uma das supervisoras, formada em Ciências, está cursando Pedagogia. Os supervisores possuem curso de pós-graduação lato sensu sendo quatro em Administração e Supervisão Escolar, três em Pré-escola e Séries Iniciais, três em Psicopedagogia, dois em Psicologia da Educação, um em Fundamentos da Educação, um em Geografia Física e um em Metodologia do Ensino à Arte. Cabe ressaltar que quatro supervisores fizeram mais de um curso de pós-graduação lato sensu. Dois supervisores citaram ter curso na área da deficiência auditiva.

Dados pessoais, profissionais e formação acadêmica das professoras:

Quadro 2 - Caracterização das Professoras

\begin{tabular}{|c|c|c|c|c|c|c|c|c|}
\hline Idade & Sexo & $\begin{array}{l}\text { Tempo de } \\
\text { magistério }\end{array}$ & $\begin{array}{l}\text { Turm- } \\
\text { a }\end{array}$ & $\begin{array}{l}\mathrm{N}^{\circ} \text { de } \\
\text { alunos }\end{array}$ & $\begin{array}{l}\text { Ensino } \\
\text { Médio }\end{array}$ & Graduação & $\begin{array}{c}\text { Pós- } \\
\text { Graduação }\end{array}$ & $\begin{array}{l}\text { Cursos } \\
\text { em EE }\end{array}$ \\
\hline 27 & $F$ & 5 anos & $\begin{array}{l}2^{\circ} \\
\text { ano }\end{array}$ & 14 & M & LP/E & EISI & \\
\hline 29 & $F$ & 5 anos & $\begin{array}{c}1^{\circ} \\
\text { ano }\end{array}$ & 21 & M & G & EE & Ad.DM \\
\hline 29 & $\mathrm{~F}$ & 3 anos & $\begin{array}{c}2^{\circ} \\
\text { ano }\end{array}$ & 23 & M & LP/E & Cursando & \\
\hline 30 & $F$ & 9 anos & $\begin{array}{l}4^{\circ} \\
\text { ano }\end{array}$ & 21 & M & LP/E & PL & \\
\hline 33 & $F$ & 4 anos & $\begin{array}{c}2^{\circ} \\
\text { ano }\end{array}$ & 19 & $\mathrm{M} / \mathrm{C}$ & P & $\begin{array}{c}\text { Cursando } \\
\text { Pp }\end{array}$ & \\
\hline 34 & $F$ & 12 anos & $\begin{array}{c}1^{\circ} \\
\text { ano }\end{array}$ & 23 & M & LP/I & PESI & \\
\hline 34 & $\mathrm{~F}$ & 16 anos & $\begin{array}{l}3^{\circ} \\
\text { ano }\end{array}$ & 21 & M & LP/I & PESI & $\begin{array}{c}\text { Ad. DM } \\
\text { SEED/- } \\
\text { PR e } \\
\text { outros }\end{array}$ \\
\hline 35 & $F$ & 5 anos & $\begin{array}{c}1^{\circ} \\
\text { ano }\end{array}$ & 17 & M & CB & GE & \\
\hline 36 & $\mathrm{~F}$ & 16 anos & $\begin{array}{l}2^{\circ} \\
\text { ano }\end{array}$ & 19 & M & $P$ & EISI & \\
\hline 41 & $F$ & 24 anos & $\begin{array}{c}2^{\circ} \\
\text { ano }\end{array}$ & 20 & M & $\mathrm{H}$ & PESI & \\
\hline 41 & $F$ & 19 anos & $\begin{array}{c}3^{\circ} \\
\text { ano }\end{array}$ & 24 & M & $\mathrm{C} / \mathrm{M}$ & PESI & \\
\hline
\end{tabular}


... continuação quadro 2

\begin{tabular}{|c|c|c|c|c|c|c|c|c|}
\hline 42 & $F$ & 25 anos & $\begin{array}{c}4^{\circ} \\
\text { ano }\end{array}$ & 16 & $M$ & P & TAPE & \\
\hline 44 & $F$ & 25 anos & $\begin{array}{c}2^{\circ} \\
\text { ano }\end{array}$ & 20 & M & P e Geo & D & \\
\hline 46 & $F$ & 27 anos & $\begin{array}{c}3^{\circ} \\
\text { ano }\end{array}$ & 22 & & P & PESI & SEMED \\
\hline 50 & $F$ & 32 anos & $\begin{array}{c}2^{\circ} \\
\text { ano }\end{array}$ & 26 & & LP/l & & \\
\hline & $F$ & & $\begin{array}{c}3^{\circ} \\
\text { ano }\end{array}$ & 16 & M & H & PESI & Ad. DM \\
\hline
\end{tabular}

Legenda: Sexo: F - Feminino. Ensino Médio: M - Magistério C - Contabilidade. Graduação: P - Pedagogia, LPE - Letras Português/Espanhol, LPI - Letras Português/ Inglês, Geo - Geografia, CB - Ciências Biológicas, $H$ - História, C/M - Ciências/ Matemática. Pós-graduação: EISI - Educação Infantil e Série Iniciais, EE - Educação Especial, PL - Português/Literatura, Pp - Psicopedagogia, PESI - Pré-escola e Séries Iniciais, GE - Gestão Escolar, TAPE - Teoria e Análise do Processo Educacional, D - Didática. Cursos em Educação Especial - Ad.DM - Adicional na área da Deficiência Mental, SEED - Secretaria Estadual de Educação Especial do Estado do Paraná, SEMED - Secretaria Municipal de Educação.

Fonte: a autora

No que diz respeito às professoras, a idade média das que responderam ao item idade é de 36,7 anos. O tempo de atuação no Magistério é, em média, 16 anos e cinco meses. Três professoras atuam no $1^{\circ}$ ano, sete no $2^{\circ}$ ano, quatro no $3^{\circ}$ ano e duas no $4^{\circ}$ ano. O número de alunos por professora varia entre 14 e 26 alunos, chegando-se a uma média de 20,12 alunos por turma.

Destes dados, chama a atenção a média de 20,12 alunos por turma. Este número difere da realidade observada nas escolas públicas brasileiras que, em geral, possuem salas superlotadas e pode ser considerado um aspecto positivo tanto para a inclusão escolar do aluno com deficiência intelectual como para o bom acompanhamento das atividades escolares de todos os alunos, ainda mais considerando a existência de um auxiliar.

Quanto à formação das professoras, 14 cursaram Magistério. Há professoras graduadas em Letras, Pedagogia, Geografia, História, Ciências Biológicas e Ciências/Matemática. Apenas uma professora não possui pós-graduação e duas encontram-se cursando, das demais, oito possuem curso de pósgraduação (lato sensu) em Educação Infantil ou Pré Escola e Séries Iniciais. Na área da Educação Especial, três professoras concluíram curso adicional em nível de Ensino Médio, na área da deficiência intelectual, uma destas acrescentou que participou de cursos oferecidos pelo Departamento de Educação Especial da Secretaria de Educação do Estado do Paraná e de cursos diversos. Apesar de todas as professoras participarem, somente uma citou os encontros de formação continuada oferecidos pela SEMED. 
Entre as professoras $56,25 \%$, declararam conhecer as necessidades educacionais de seus alunos com deficiência intelectual e $43,75 \%$, as conhecem parcialmente.

Como fontes de informações sobre as necessidades educacionais de seus alunos, $90 \%$ das professoras indicaram o contato com o aluno em sala de aula, $68,75 \%$ receberam informações sobre as necessidades educacionais especiais de seus alunos através de profissionais da equipe pedagógica da escola, profissionais da APAE, professora anterior do aluno, professora da sala de recursos multifuncionais e mãe do aluno. $68,75 \%$ indicaram a leitura de pareceres pedagógicos, 56,25\%, avaliação pedagógica ou psicopedagógica, $50 \%$ avaliação psicopedagógica e 37,5\% diagnóstico, avaliação ou parecer de outros profissionais, como: psicóloga, neuropediatra e psicopedagoga.

Analisando as fontes de informações indicadas fica evidente a importância dos serviços de apoio na avaliação e acompanhamento do processo evolutivo dos alunos com deficiência intelectual. Pois, entre as nove professoras que responderam conhecer as necessidades educacionais de seus alunos, sete tiveram contato com avaliações e diagnósticos de outros profissionais. Entre as sete que afirmaram conhecer parcialmente, apenas uma afirmou tê-las conhecido através da leitura de avaliações e diagnósticos de outros profissionais. Isso indica que, além do contato com o próprio aluno, a troca de informações com pessoas de seu convívio, com profissionais da área da educação comum e especial ou mesmo com profissionais de outras áreas, como a da saúde, é essencial para se traçar um plano de trabalho. Ainda que algumas das necessidades dos educandos, num primeiro plano, não sejam da ordem das necessidades educacionais, podem refletir-se nelas. Conforme Mazzotta (1998), é importante que atendimentos na área social, da saúde ou outros, ocorram de forma integrada e cooperativa com a educação escolar.

Segundo as professoras, é na área acadêmica que seus alunos mais necessitam de apoio. As duas professoras que não indicaram esta área foram as que lecionam para alunos que apresentam deficiência física associada à intelectual. Para estas, a maior necessidade de apoio está nas atividades de manuseio do material escolar, locomoção, alimentação e higiene pessoal.

Nas 10 escolas participantes da pesquisa, o auxiliar foi solicitado à SEMED. Supervisores e professoras elencaram como atribuições dos auxiliares: ajudar o aluno com deficiência intelectual em tarefas acadêmicas, em atividades de locomoção, higiene e alimentação, no desenvolvimento de sua autonomia, além de auxiliar a professora, preparar atividades específicas para o aluno com deficiência intelectual, ajudar os demais alunos da turma e cuidar para que o aluno não se machuque, ou agrida alguém.

Observa-se que nem todas as atribuições enumeradas têm caráter essencialmente pedagógico, ou exigem conhecimentos nesta área, sendo pos- 
sível pensar que o auxiliar, conforme a necessidade do aluno, não necessariamente deva ser um profissional da educação.

Todavia, destaca-se o fato de $68,75 \%$ das professoras citarem que o auxiliar não se dedica exclusivamente ao aluno com deficiência intelectual, mas sim a toda a turma e $12,5 \%$ das professoras acrescentaram que auxiliam diretamente seus alunos. Desta forma, se a função a ser exercida não se resume em auxiliar apenas o aluno com deficiência, mas sim a professora no que diz respeito ao processo pedagógico que envolve a turma como um todo, o ideal será que o auxiliar seja um profissional da educação.

Entre os supervisores, $70 \%$ afirmaram orientar o auxiliar quanto as suas atribuições. Entre os professores este número sobe para 100\%.

Ainda que não seja a quantidade, mas sim a qualidade das orientações que assegura um bom trabalho em sala de aula, há discrepância entre a quantidade de momentos destinados pelas professoras para a orientação aos auxiliares. Enquanto $62,5 \%$ orientam apenas no decorrer da aula, apenas duas o fazem em quatro dos cinco momentos sugeridos: início da aula, decorrer da aula, hora-atividade, reuniões específicas, outro momento. Dos dez supervisores, oito informaram que as orientações acontecem sempre que necessário ou durante as horas-atividade das professoras.

Entre os supervisores, 90\% responderam que se sentem parcialmente preparados para orientar os auxiliares e $10 \%$ responderam não se sentirem preparados. Entre as professoras $56,25 \%$ sentem-se parcialmente preparadas, $6,25 \%$ não se sente preparada e $36,5 \%$ consideram-se preparadas para orientar os auxiliares.

Comparando as respostas dos supervisores e professoras, ressaltase o fato de que nenhum dos supervisores se considera preparado, enquanto que entre as professoras este número chega a seis. Destas, apenas uma tem formação na área de Educação Especial. As outras duas professoras que possuem curso nesta área citam sentirem-se apenas parcialmente preparadas para orientar seus auxiliares. Este fato indica não haver relação entre ter formação e considerar-se preparada para orientar os auxiliares.

Supervisores e professoras consideraram que o trabalho desenvolvido pelos auxiliares contribuiu para o desenvolvimento acadêmico e social do aluno com deficiência intelectual. Apenas uma professora considerou que o trabalho do auxiliar não contribuiu para o desenvolvimento da autonomia do aluno. Entretanto, situações de dependência do aluno em relação ao auxiliar foram citadas pelos sujeitos em outros itens dos questionários e da entrevista.

Quanto às sugestões para a melhoria do resultado de seu trabalho em relação ao aluno com necessidades educacionais especiais, no que se refere à 
presença do auxiliar em sala de aula, $80 \%$ dos supervisores e $87,5 \%$ das professoras citam a questão da formação, inicial ou continuada, destinada aos supervisores, professores ou auxiliares.

Entre os supervisores, $50 \%$ justificam a presença do auxiliar em sala de aula pela necessidade de um atendimento individualizado aos alunos com deficiência intelectual, 30\% evidenciam a importância do auxiliar em situações nas quais as atividades, conteúdos e tempo devem ser adaptados ou flexibilizados de acordo com as necessidades destes alunos, $10 \%$ na interação deles com colegas e professores e $10 \%$ na mediação para a aquisição de conhecimentos por parte do aluno.

Para os supervisores e professoras entrevistados, a inclusão escolar representa um direito que não diz respeito somente aos alunos com deficiência, envolve o acolhimento, o respeito às diferenças e o apoio às necessidades.

Há nos conceitos sobre deficiência intelectual dos sujeitos a premissa de que, mesmo com limitações, os alunos com essa deficiência aprendem e por vezes necessitarão de recursos e tempo diferenciados para isso. Entretanto, um supervisor e uma professora expressaram sua dificuldade em compreender tal deficiência.

Os principais objetivos em relação aos alunos com deficiência intelectual versaram sobre desenvolvimento de potencialidades, aceitação em sala de aula, integração social, objetivos acadêmicos, entre estes, ler e escrever.

Para os supervisores e professoras entrevistados, a inclusão escolar e seus fatores facilitadores e dificultadores estão pautados em questões atitudinais da comunidade escolar e da família, de organização de espaços e apoios necessários e reconhecidos como indispensáveis para os alunos, além das condições de saúde do aluno.

No que diz respeito às condições de apoio à inclusão, supervisores relataram que os auxiliares proporcionam uma ajuda importante em sala de aula, mas sugerem que o professor conseguiria trabalhar sem a sua presença. Porém, as professoras afirmaram que seu trabalho sem o auxiliar seria prejudicado. Supervisores e professoras apresentam ressalvas quanto à formação e perfil dos auxiliares contratados.

Em relação às condições de apoio, cabe ressaltar que os alunos com deficiência intelectual das professoras entrevistadas frequentam salas de recursos multifuncionais, que funcionam em suas próprias escolas ou em escolas próximas as suas.

Supervisores e professoras consideraram essas salas um apoio fundamental à aprendizagem e suas professoras mais preparadas para trabalhar 
com alunos com deficiência intelectual por possuírem formação específica na área.

\section{Conclusões}

$\mathrm{Na}$ realidade estudada um dos aspectos que chama a atenção é a média de 20,12 alunos por sala. Este é um fator facilitador da inclusão escolar de alunos com deficiência intelectual. Além disso, cada professora participante da pesquisa conta com um auxiliar, que foi solicitado à Secretaria Municipal de Educação pela própria escola.

O critério para a contratação de estagiário é a presença em sala de aula de um ou mais alunos com diagnóstico de deficiência intelectual, deficiência física, hiperatividade ou transtorno global do desenvolvimento. Entretanto, no município, não há nenhuma norma técnica que especifique quando e porque esse auxiliar deve ser contratado e quais suas atribuições.

Tal posicionamento dá margem a ações condizentes à visão estática sobre a relação entre educandos e a educação escolar que, segundo Mazzotta (1998), indica a correspondência necessária entre educação especial para alunos percebidos como especiais e educação comum para alunos percebidos como comuns. Sabe-se que diferentes graus de severidade de deficiência e as condições individuais exigem diferentes formas de apoio.

Para tanto, além do contato com o aluno em sala de aula, de pareceres pedagógicos sobre a vida escolar do aluno e informações obtidas com pessoas do convívio do aluno, suas necessidades educacionais comuns ou especiais podem ser conhecidas e melhor compreendidas à luz de avaliações e diagnósticos criteriosos de profissionais de apoio à educação ou de outras áreas.

Apesar das professoras indicarem que é na área acadêmica que seus alunos com deficiência intelectual mais necessitam de apoio, este quadro é alterado quando se trata de alunos com deficiência múltipla, caracterizada pela deficiência física associada à intelectual. Para estes, a maior necessidade de apoio se apresentou nas atividades de manuseio do material escolar, locomoção, alimentação e higiene pessoal.

Supervisores e professoras elencaram como atribuições dos auxiliares: ajudar o aluno com deficiência intelectual em tarefas acadêmicas, em atividades de locomoção, higiene e alimentação, no desenvolvimento de sua autonomia, além de auxiliar a professora, preparar atividades específicas para o aluno com deficiência intelectual, ajudar os demais alunos da turma e cuidar para que o aluno não se machuque, ou agrida alguém.

Neste ponto cabe ressaltar que o Parecer CNE no 13 de 2009 inclui entre os profissionais da educação os responsáveis pelas atividades de alimentação, higiene e locomoção (BRASIL, 2009). 
Observa-se que tais atribuições não exigem do auxiliar conhecimentos pedagógicos. Plausível cogitar, que este não necessariamente deva ser, ou seja considerado, um profissional da educação. Entretanto, caso sua função envolva o apoio ao professor no encaminhamento pedagógico junto a seus alunos, o auxiliar deveria ter, ou ao menos estar em formação na área da Educação.

Entre as professoras, verificou-se preocupação com o desenvolvimento da autonomia do aluno. Todavia, cabe ressaltar que existe uma diferença entre o auxiliar ajudar outros alunos simplesmente para evitar que o aluno com deficiência intelectual se torne dependente e o auxiliar receber orientações sobre como interagir com este aluno, de forma a desenvolver sua autonomia e iniciativa.

O posicionamento das professoras que afirmam auxiliar diretamente seus alunos com deficiência intelectual é muito importante, evidencia que a intervenção pedagógica direcionada a estes, não está somente sob a responsabilidade dos auxiliares.

Professores e demais profissionais da escola comum dizem não estar preparados para a inclusão escolar de alunos com deficiência tendo como principal justificativa a falta de formação específica.

Curiosamente, entre as professoras que responderam sentirem-se preparadas para orientar seus auxiliares, encontravam-se professoras sem formação na área da Educação Especial e entre as que se sentiam parcialmente preparadas, estavam professoras que possuem formação específica. Tal fato evidenciou não haver relação entre ter formação na área e auto avaliar-se como tendo preparo para orientar os auxiliares.

Ainda assim, os participantes da pesquisa sugeriram a contratação de profissionais com curso na área da Educação Especial ou estagiários do curso de Pedagogia e enfatizaram a necessidade de cursos de formação continuada para si mesmos e para os auxiliares.

Supervisores e professoras consideraram que o trabalho do auxiliar contribui para o desenvolvimento acadêmico e social do aluno com deficiência intelectual, havendo ressalvas em relação ao desenvolvimento da autonomia, como pode ser verificado nas palavras de uma das supervisoras entrevistadas:

Para mim, a auxiliar, ela é perigosa. Ao mesmo tempo que ela ajuda, ela se torna uma coisa meio perigosa para a criança. A criança fica dependente sim, da auxiliar. Se ela ficar com só com aquela criança, sentada do lado, como a gente vê acontecer, aquela criança vai ter dependência. Ela só vai executar e fazer quando a auxiliar tiver junto, senão ela não vai fazer e não é esse o objetivo da escola. O objetivo é criar a independência deles. 
As justificativas das respostas dos supervisores e professoras que consideraram que o trabalho desenvolvido pelo auxiliar em sala de aula contribuiu para o desenvolvimento dos alunos com deficiência intelectual, pautaramse mais nas atividades desenvolvidas pelos auxiliares e na importância da sua presença em classe, do que em evidências do desenvolvimento alcançado pelos alunos.

Foram citados mais progressos na área social e menos na área acadêmica. Cabe ressaltar que entre as áreas de maior necessidade de apoio apontadas pelas professoras, a menos citada foi a social e a mais citada foi a acadêmica. O que evidencia o desafio em que se constitui a inclusão de alunos com deficiência intelectual diante dos objetivos educacionais do Ensino Fundamental.

Face ao exposto, supervisores e professoras citam como fatores facilitadores da inclusão em suas escolas o acolhimento ao aluno, o comprometimento da equipe pedagógica, a troca de informações com as professoras das salas de recursos multifuncionais frequentadas pelos alunos, a presença do auxiliar em sala de aula e a participação da família.

Com base na análise dos dados obtidos, acredita-se que a atuação dos profissionais da educação na inclusão escolar de alunos com deficiência intelectual poderia se beneficiar através de ações desenvolvidas pela Secretaria Municipal da Educação como: elaboração de normas para a contratação dos auxiliares, determinação das atribuições dos auxiliares de acordo com as necessidades que se configuram no contexto escolar em que o aluno com deficiência intelectual está inserido e continuidade na oferta de formação continuada.

No âmbito das unidades escolares, sugere-se a sistematização das orientações aos auxiliares, avaliação periódica dos resultados de sua atuação, garantia de acesso aos professores às avaliações e diagnósticos dos alunos e sistematização da interação entre os profissionais do ensino comum e do atendimento educacional especializado.

\section{Referências}

ASSOCIAÇÃO AMERICANA DE RETARDO MENTAL. Retardo Mental: definição, classificação e sistemas de apoio. Tradução de Magda França Lopes. 10. ed. Porto Alegre: Artmed, 2006.

BRASIL. Ministério da Educação. Lei de Diretrizes e Bases da Educação Nacional. LDB 9.394, de 20 de dezembro de 1996. Disponível em: <http:// portal.mec.gov.br/arquivos/pdf >.Acesso em: 8 maio 2010.

. Ministério da Educação. CNE/CEB. Resolução ${ }^{\circ} \mathbf{2}$ de $\mathbf{1 1}$ de setembro de 2001. Institui Diretrizes Nacionais para a Educação Especial na Educação Básica. Disponível em: <http://portal.mec.gov.br/cne/arquivos/pdf/ CEB0201.pdf >. Acesso em 8 maio 2010. 
. Ministério da Educação. SEESP. Evolução da Educação Especial no Brasil. Brasília: MEC/SEE, 2006 (b). Disponível em: < http:// portal.mec.gov.br/seesp/arquivos/pdf/brasil.pdf >. Acesso em 10 maio 2010.

. Ministério da Educação. SEESP. Política Nacional de Educação Especial na Perspectiva da Educação Inclusiva. 2008. Disponível em: < http://portal.mec.gov.br/seesp/arquivos/pdf/politica.pdf >. Acesso em 08 maio 2010.

Ministério da Saúde. Conselho Nacional de Saúde. Comissão Nacional de Ética em Pesquisa. Manual Operacional para Comitês de Ética em Pesquisa. 4.ed. Rev. atual. Brasília: Editora do Ministério da Saúde, 2008. Disponível em: < http://conselho.saude.gov.br/Web_comissoes/conep/aquivos/ materialeducativo/Manual_ceps_v2.pdf. Acesso em 16 mar. 2012.

MEC. CNE/CEB. Parecer 13/2009. Diretrizes Operacionais para o atendimento educacional especializado na Educação Básica, modalidade Educação Especial. Disponível em < http://portal.mec.gov.br/dmdocuments/pceb013 09 homolog.pdf >. Acesso em: 25 mar. 2011.

LIBÂNEO, J.C. Organização e Gestão da Escola: teoria e prática. 5.ed. rev. amp. Goiânia: Alternativa, 2004.

LÜDKE, M.; ANDRÉ, M.E.D.A. Pesquisa em educação: abordagens qualitativas. São Paulo: EPU - Editora Pedagógica e Universitária LTDA, 1986.

MAZZOTTA, M. J. S. Fundamentos de Educação Especial. São Paulo: Pioneira, 1982.

Educação Especial: comum ou especial? São Paulo: Pioneira, 1987.

. Inclusão e integração ou chaves da vida humana. In: CONGRESSO

IBERO- AMERICANO DE EDUCAÇÃO ESPECIAL,3, 1998, Foz do Iguaçu. Anais... Disponível em: < http://www.educacaoonline.pro.br/ index.php?option $=$ com_content $\&$ view $=$ article $\&$ catid $=6$ : educacaoinclusiva\&id=96:inclusao-e-integracao-ou-chaves-da-vida-humana $>$. Acesso em: 20 abr. 2011.

Educação Especial no Brasil: história e políticas públicas. 4.ed. São Paulo: Cortez, 2003.

Reflexões sobre inclusão com responsabilidade. In Revista @mbiente e ducação, São Paulo, v. 1, n. 2, p. 165-168, ago./dez. 2008. Disponível em: < http://www.cidadesp.edu.br/old/revista_educacao/pdf/volume_2/ rev_n\%C2\%BA2_13_mazzotta.pdf >. Acesso em: 21 abr. 2011.

PARANÁ. Secretaria de Estado da Educação Superintendência da Educação. Coordenação de Gestão Escolar. Caderno de apoio para elaboração do regimento escolar. Curitiba: SEED - PR, 2007. - 124 p. Disponível em: < 
http://www.diaadiaeducacao.pr.gov.br/diaadia/diadia/arquivos/File/escola/ Regimento\%20Escolar.PDF >. Acesso em: 06 maio 2011.

SAMPIERI, R. H., COLLADO, C. F., LUCIO, P. B. Metodologia de Pesquisa. São Paulo: MacGrawHill, 2006.

\section{Correspondência}

Anaí Cristina da Luz Stelmachuk - Rua da Consolação, 890, CEP 01302-907, São Paulo, São Paulo, Brasil.

E-mail: anai_stelmachuk@yahoo.com.br - marmaz@mackenzie.br

Recebido em 16 de abril de 2012

Aprovado em 11 de maio de 2012 